\title{
Endothelin-2 Injures the Blood-Retinal Barrier and Macroglial Müller Cells
}

\section{Interactions with Angiotensin II, Aldosterone, and NADPH Oxidase}

\author{
Saeed F. Alrashdi, Devy Deliyanti, Dean M. Talia, and Jennifer L. Wilkinson-Berka
}

From the Department of Diabetes, Monash University, Melbourne, Victoria, Australia

\author{
Accepted for publication \\ November 7, 2017. \\ Address correspondence to \\ Jennifer L. Wilkinson-Berka, \\ Ph.D., Department of Diabetes, \\ The Central Clinical School, \\ Monash University, Level 5, \\ The Alfred Centre, 99 Com- \\ mercial Rd., Melbourne, Victo- \\ ria, Australia, 3004. E-mail: \\ jennifer.wilkinson-berka@ \\ monash.edu.
}

\begin{abstract}
Although increasing evidence indicates that endothelin-2 (Edn2) has distinct roles in tissue pathology, including inflammation, glial cell dysfunction, and angiogenesis, its role in the retina and the factors that regulate its actions are not fully understood. We hypothesized that Edn2 damages the blood-retinal barrier (BRB) and that this is mediated by interactions with the renin-angiotensin-aldosterone system and reactive oxygen species derived from NADPH oxidase (Nox). C57BL/6J mice received an intravitreal injection of Edn2 or control vehicle to examine the blood pressure-independent effects of Edn2. Mice administered Edn2 were randomized to receive by intraperitoneal injection treatments that inhibited the Edn type a receptor, Edn type b receptor, angiotensin type 1 receptor, mineralocorticoid receptor, or Nox isoforms 1 to 4. One month later, mice administered Edn2 exhibited breakdown of the BRB with increased vascular leakage, vascular endothelial growth factor expression, and infiltrating macrophages $\left(\right.$ Ly6C $\left.^{+} \mathrm{CD} 45^{\text {high }} \mathrm{CD} 11 \mathrm{~b}^{+}\right)$. Further, macroglial Müller cells, which influence the integrity of the BRB and prevent retinal edema, became gliotic and expressed increased levels of water (aquaporin-4) and ion (Kir4.1) channels. This Edn2-mediated retinopathy was reduced by all treatments. Complementary in vitro studies in cultured Müller cells supported these findings and demonstrated the importance of reactive oxygen species in mediating these events. In conclusion, Edn2 has detrimental effects on the BRB and Müller cells that involve interactions with the renin-angiotensin aldosterone system and Nox1/4. (Am J Pathol 2018, 188: 805-817; https://doi.org/10.1016/j.ajpath.2017.11.009)
\end{abstract}

Endothelins (Edns) are powerful vasoconstrictors comprised of three isoforms, denoted Edn1, Edn2, and Edn3, that exert their actions by two $G$ protein-coupled receptors, Edn type A (Ednra) and Edn type B (Ednrb). ${ }^{1}$ Of the three Edns, Edn1 is considered to have the most potent effects on the vasculature, $^{2}$ influencing blood flow in various tissues, including the retina. ${ }^{3-5}$ Edn 1 is also a powerful mitogen, modulating cell proliferation in a number of diseases. ${ }^{6}$ Far less is known about the actions of Edn2, which may largely be due to the assumption that Edn 2 has comparable actions with Edn 1 because of the similarity between their structures (differing by only two amino acids in humans), and their equal affinity for both the Ednra and Ednrb. ${ }^{1}$ However, there is growing evidence that Edn2 has distinct roles such as promoting inflammation, ${ }^{7-9}$ angiogenesis in the ovary, ${ }^{10}$ and glial cell dysfunction in the brain. ${ }^{11}$

The high levels of Edn2 transcripts in the retina of preclinical models of retinopathy of prematurity ${ }^{12}$ and diabetic retinopathy ${ }^{13}$ potentially implicated Edn2 in the development of retinal vascular disease. Indeed, it has been

Supported by the Ministry of Education of Saudi Arabia PhD scholarship 1021389984 (S.F.A.), JDRF postdoctoral fellowship 3-PDF-2017-376-A-N (D.D.), and National Health and Medical Research Council of Australia project grant 1078442 (J.L.W.-B.).

Disclosures: None declared. 
suggested that elevated circulating levels of Edn2 may be a biomarker for diabetic retinopathy. ${ }^{13}$ A hallmark feature of these neovascular retinopathies is breakdown of the blood-retinal barrier (BRB) that results in sight-threatening vascular leakage and hemorrhages into the retina and vitreous cavity as well as retinal edema. The integrity of the BRB is highly influenced by Müller cells. ${ }^{14,15}$ These macroglia provide a supporting framework for the retinal vasculature, are a source of vascular endothelial growth factor $(\mathrm{Vegf})^{16}$ that promotes vascular permeability and proliferation in the retina, ${ }^{16,17}$ and are critical for preventing retinal edema by regulating ion and fluid transport. ${ }^{14}$ Both the Ednra and Ednrb are expressed on Müller cells ${ }^{18}$; however, it is not clear if Edn2 promotes damage to Müller cells and disrupts the BRB. Further, the factors regulating the actions of Edn2 in the retina have not been fully explored.

Studies of the cardiovascular system have identified that the renin-angiotensin-aldosterone system (RAAS) is one of the most important regulators of the Edn system, albeit this relationship is highly complex. ${ }^{19}$ The vasoactive factors, angiotensin II (Ang II) and aldosterone are key effector molecules of the RAAS and can influence the expression of $E d n 1^{20-22}$ and potentiate its effects on blood pressure. ${ }^{19}$ Potential interactions between the RAAS and Edn2 are less well known and to our knowledge have not been investigated in the retina or in the context of the BRB and Müller cell dysfunction. Of relevance is that a local RAAS exists in the retina, and key cognate receptors of Ang II and aldosterone, the angiotensin type 1 receptor (Agtr1) and the mineralocorticoid receptor (Mlr), respectively, are expressed on Müller cells ${ }^{23,24}$ and have been demonstrated to have a causal role in neovascular retinopathies. ${ }^{25,26}$

Increasing evidence indicates that one mechanism whereby Ang II and aldosterone promote vascular pathology is by their up-regulation of reactive oxygen species (ROS) derived primarily from the NADPH oxidase (Nox) family of enzymes. ${ }^{27,28}$ This may also be the situation for the Edns because the expression of certain isoforms of Nox are increased by Edn1. ${ }^{29,30}$ However, if Edn2 and Nox interact in tissues and influence the integrity of the BRB and Müller cells in the retina is unknown.

To delineate the specific role of Edn2 in the retina and its potential interactions with other pathways, Edn2 was administered to mice by an intraocular route to determine whether Edn2 influenced retinal pathology independently of any systemic effects on blood pressure. The response of Edn2 was evaluated after antagonism of the key receptors of the Edn system and RAAS, as well as Nox isoform inhibition. Indeed, we demonstrated that Edn2 caused profound changes in the integrity of the BRB, which included the infiltration of immune cells, vascular leakage, and damage to retinal Müller cells. The ability of inhibitors of the Agtr1, Mlr, and Nox isoforms 1 to 4 to attenuate retinal injury, findings that were confirmed in vitro for Müller cells, highlighted the complex interactions between these vasoactive systems that are likely to be pertinent to the pathogenesis, progression, and ultimately management of various neovascular retinal diseases.

\section{Materials and Methods}

\section{Animals}

All studies were approved by the Alfred Medical Research and Education Precinct Animal Ethics Committee (Melbourne, VIC, Australia). C57BL/6J mice and SpragueDawley rats were purchased from the Animal Resources Center (Perth, WA, Australia) and housed in the Alfred Medical Research and Education Precinct Animal Services. All animals were housed at $22^{\circ} \mathrm{C} \pm 1{ }^{\circ} \mathrm{C}$ with a 12-hour light/dark cycle and received normal rodent chow (Specialty Feeds; Glen Forrest, WA, Australia) and drinking water $a d$ libitum.

\section{Intravitreal Administration of Edn2}

Six-week-old female mice were randomized to receive into each eye, one 1- $\mu \mathrm{L}$ intravitreal injection of control vehicle $(0.001 \%$ N,N-Dimethylformamide; Sigma-Aldrich, St. Louis, MO) or mouse Edn2 peptide (CSCNSWLDKECVYFCHLDIIW; $500 \mu \mathrm{mol} / \mathrm{L}$; GL Biochem, Shanghai, China). The dose of Edn2 was based on previous studies. ${ }^{31}$ Intravitreal injections were performed according to previously published method. ${ }^{32}$ In brief, mice were anesthetized with an intraperitoneal injection of $40 \mathrm{mg} / \mathrm{kg}$ ketamine and $10 \mathrm{mg} / \mathrm{kg}$ xylazine, and a Hamilton syringe attached to a 31-gauge needle was inserted 1 to $2 \mathrm{~mm}$ into the eye and $2 \mathrm{~mm}$ behind the limbus at a 45-degree downward angle to avoid the lens. Mice were then randomized to receive by daily intraperitoneal injection in a $100-\mu \mathrm{L}$ volume, the Ednra blocker, BQ123 $(1 \mathrm{mg} / \mathrm{kg}$ in sterile water; Sigma-Aldrich), the Ednrb blocker BQ788 $(0.5 \mathrm{mg} / \mathrm{kg}$ in $0.0001 \%$ dimethylsulfoxide; Sigma-Aldrich), the Agtr1 blocker, valsartan $(10 \mathrm{mg} / \mathrm{kg}$ in $0.1 \mathrm{~mol} / \mathrm{L}$ Tris buffer; Novartis Pharma, Somerville, NJ), the Mlr blocker, spironolactone (25 mg/kg in 10\% dimethylsulfoxide/90\% olive oil; SigmaAldrich), or the Nox1/4 inhibitor, GKT137831 (60 mg/kg per day in 25\% dimethylsulfoxide; Genkyotex, Geneva, Switzerland). As described previously, GKT137831 is an efficient inhibitor with equal affinity for both Nox 1 and Nox 4 isoforms (Ki 100 to $150 \mathrm{nmol} / \mathrm{L}$ and $\mathrm{E}_{\max }>90 \%$ ). ${ }^{33,34}$ The doses of these treatments were based on previous studies. ${ }^{25,33,35}$ One month later, mice were humanely euthanized with $170 \mathrm{mg} / \mathrm{kg}$ sodium pentobarbitone (Virbac, Peakhurst, NSW, Australia) and retinas were collected. Body weight was measured at the end of the study ( $n=12$ to 21 mice per group).

qPCR

Real-time quantitative PCR (qPCR) was performed as described previously. ${ }^{23,33}$ The primer sequences are found in Table 1. Total RNA was isolated from single retina by 
using the RNeasy mini kit (Qiagen, Doncaster, VIC, Australia). Retinas comprised most of the tissue from the retinal surface (inner limiting membrane) to the photoreceptor layer. Total RNA was separately acquired from the outermost layer of the retina, the retinal pigment epithelium (RPE) and the associated vascular choroid. RNA $(1 \mu \mathrm{g})$ from these tissues were subjected to DNase treatment (DNA-free kit; Ambion, Carlsbad, CA) and reverse transcription (First-Strand cDNA synthesis kit; Roche, Basil, Switzerland). Four to seven mice per experimental group were evaluated. For cultured rat Müller cells (see below), RNA was extracted by using the RNeasy mini kit (Qiagen) and $500 \mathrm{ng}$ of RNA was used. mRNA expression was normalized to 18s rRNA endogenous control, and the relative fold difference in expression was calculated by using the comparative $2^{-\Delta \Delta \mathrm{Ct}}$ method.

\section{Enzyme-Linked Immunosorbent Assay}

Retinal vascular leakage was measured by quantitating albumin levels in single retina (excluding RPE/choroid) according to previously published method ${ }^{23}$ by using a mouse albumin enzyme-linked immunosorbent assay kit
(Bethyl Laboratories, Montgomery, TX). Values were normalized to dry retinal weight, and four to six mice per group were evaluated. With the use of an established protocol in cultured rat Müller cells, ${ }^{33}$ protein levels of monocyte chemoattractant protein-1 (Mcp1; eBioscience, San Diego, CA) were evaluated in cell supernatant.

\section{Flow Cytometry of Retina}

Both retinas from each mouse were pooled and digested in 1 $\mathrm{mg} / \mathrm{mL}$ collagenase and $15 \mathrm{U} / \mathrm{mL}$ DNase in RPMI 1640 for 15 minutes at $37^{\circ} \mathrm{C}$. The homogenized tissue was filtered through a $40-\mu \mathrm{m}$ strainer (BD Biosciences, San Jose, CA), and enzyme activity was quenched with fluorescent activated cell sorting (FACS) buffer (phosphate-buffered saline with $2 \%$ fetal calf serum and $0.1 \%$ sodium azide). The cells were then exposed to Fc Block (BD Biosciences) and resuspended in FACS buffer that contained rat antimouse CD45-BV786 (dilution 1:500; clone 30-F11), CD11b-AF700 (dilution 1:200; clone M1/70; BD Biosciences), and Ly6C-BV605 (dilution 1:500; clone AL-21; BD Biosciences) for 45 minutes at $4^{\circ} \mathrm{C}$. FACS analysis was performed on a BD LSR II flow cytometer (BD

Table 1 Primer Sequences Used in Real-Time Quantitative PCR

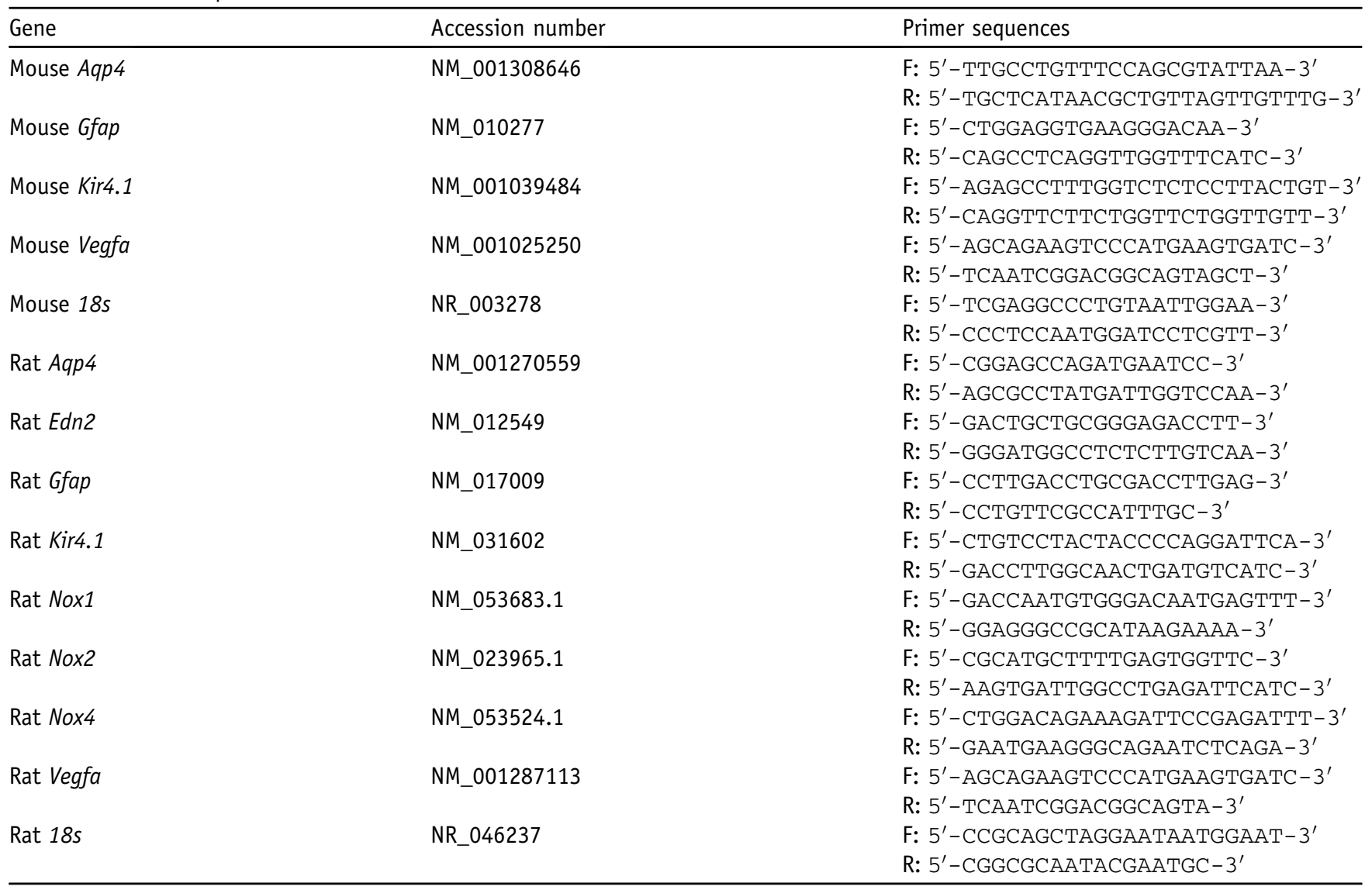

Accession numbers are found at https://www.ncbi.nlm.nih.gov/nuccore.

$F$, forward primer; $R$, reverse primer. 
Biosciences). Total retinal cell counts were performed with an automated cell counter (Countess II FL; Life Technologies, Scoresby, VIC, Australia). Dead cells were excluded through staining with either propidium iodide or Invitrogen LIVE/DEAD Fixable Aqua (Life Technologies). A minimum of one million events were collected per sample and analyzed with FlowJo software version 10.1 (Tree Star, Ashland, OR). Results are expressed as absolute numbers of $\mathrm{CD} 45^{\text {high }} \mathrm{CD} 11 \mathrm{~b}^{+} \mathrm{Ly} 6 \mathrm{C}^{+}$gated cells in the whole retina. Four to five mice per group were evaluated.

\section{Immunohistochemistry}

Immunohistochemistry was performed on 3- $\mu \mathrm{m}$ paraffin sections to identify microglia/macrophages [ionized calcium binding adaptor molecule-1 (Iba1); dilution 1:100; Wako, Tokyo, Japan], damaged Müller cells [glial fibrillary acidic protein (Gfap); dilution 1:500; DakoCytomation, Glostrup, Denmark], the water channel aquaporin-4 (Aqp4; dilution 1:200; Alamone Labs, Jerusalem, Israel), and the potassium channel Kir4.1 (dilution 1:400; Alamone Labs). Protocols followed established methods ${ }^{33}$ with sections of retina incubated overnight at $4{ }^{\circ} \mathrm{C}$ with each antibody. A negative control (phosphate-buffered saline instead of the primary antibody) and isotype $\operatorname{IgG}$ control were included in each experiment. Iba1, Aqp4, and Kir4.1 immunolabeling were visualized with a Vectastain $\mathrm{ABC}$ standard kit (Vector Laboratories Inc., Burlingame, $\mathrm{CA}$ ) and 3,3'-diaminobenzidine substrate chromagen system (DakoCytomation). Gfap immunolabeling was visualized with Alexa Fluro 488-conjugated goat antirabbit IgG (dilution 1:200; Life Technologies). For quantitation, eight sections at least $60 \mu \mathrm{m}$ apart were randomly selected from each eye. In each section, four nonoverlapping fields that spanned the entire retina were captured at $\times 400$ magnification by using a Spot digital camera (Scitech, Perth, WA, Australia). ImageJ version 1.47 (NIH, Bethesda, MD) was used to set a threshold for immunolabeling, which was applied to all fields. Five to seven mice per group were evaluated.

\section{Primary Cultures of Müller Cells}

The method to establish and characterize the primary culture of rat Müller cells was described previously. ${ }^{25,33}$ Separate dishes that contained Müller cells were untreated or administered $1 \mathrm{ng} / \mathrm{mL}$ Edn2. Additional dishes were coadministered $1 \mathrm{ng} / \mathrm{mL}$ Edn2 plus $10 \mu \mathrm{mol} / \mathrm{L}$ BQ123, 10 $\mu \mathrm{mol} / \mathrm{L} \quad$ BQ788, $10 \mu \mathrm{mol} / \mathrm{L}$ valsartan, $0.5 \mu \mathrm{mol} / \mathrm{L}$ spironolactone, or $10 \mu \mathrm{mol} / \mathrm{L}$ GKT137831 for 24 hours. In separate experiments, Müller cells were administered 100 $\mathrm{nmol} / \mathrm{L}$ Ang II or $100 \mathrm{nmol} / \mathrm{L}$ aldosterone and coadministered $10 \mu \mathrm{mol} / \mathrm{L} \mathrm{N}$-acetylcysteine or $10 \mu \mathrm{mol} / \mathrm{L}$ diphenyliodonium for 24 hours. The dose of each agent was based on previous studies. ${ }^{18,25,36}$ Experiments were repeated three times with three replicates in each experiment.

\section{Western Blot Analysis}

Methods are described previously. ${ }^{33}$ Cultured Müller cells and retinas were homogenized in RIPA buffer that contained 1:100 protease and phosphatase inhibitor cocktail (Sigma-Aldrich). Total protein levels were quantitated by using the Bio-Rad assay. Fifty microgram of protein was fractionated by SDS gel electrophoresis and transferred to polyvinylidene difluoride membranes (Bio-Rad, Hercules, CA). Membranes were incubated overnight at $4^{\circ} \mathrm{C}$ with the following antibodies: rabbit anti-extracellular-signal-regulated kinase (ERK)1/2 (dilution 1:1000), rabbit antiphosphorylated ERK1/2 (dilution 1:500; Cell Signaling Technology Inc., Danvers, MA), a rabbit anti-VEGF (dilution 1:500; Santa Cruz Biotechnology, Dallas, TX), rabbit anti-zona occludin-1 (ZO-1) (dilution 1:500; Invitrogen, Carlsbad, CA), and mouse anti-claudin-5 (dilution 1:500; Thermo Fisher Scientific, Hanover Park, IL). Membranes were then washed and stained with a goat anti-rabbit or mouse IgG or conjugated with horseradish peroxidase (dilution 1:4000) for 1 hour at room temperature. Membranes were developed by using the enhanced chemiluminescence kit (Thermo Fisher Scientific) and a film developer and then washed in tris-buffered saline and Tween 20 overnight and incubated with an anti- $\beta$-actin antibody (dilution 1:1000; Cell Signaling Technology Inc.) as loading controls. Quantitation was performed with the Bio-Rad Quantity One 1-D analysis software version 4.6.8, and optical densities were expressed as the ratio between corresponding protein and $\beta$-actin.

\section{Dihydroethidium Staining for ROS Measurements}

Primary rat retinal Müller cell cultures were washed for 2 minutes with Hanks balanced salt solution, followed by incubation with $5 \mu \mathrm{mol} / \mathrm{L}$ dihydroethidium (Sigma-Aldrich) at $37^{\circ} \mathrm{C}$ in $5 \% \mathrm{CO}_{2}$ in the dark for 30 minutes. Cells were then washed with Hanks balanced salt solution, followed by immediate imaging with an Eclipse TE2000 inverted fluorescence microscope (Nikon Instruments Inc., Melville, NY). The fluorescence intensity of cells was used as a measure of intracellular ROS levels by using ImageJ software version 1.47 (NIH). ${ }^{33}$

\section{Statistical Analysis}

All data were analyzed with the GraphPad Prism software version 5 (GraphPad Software, San Diego, CA). Normality was assessed by the Pearson, Shapiro-Wilk, and KolmogoroSmirnov normality tests. Analyses were performed using a one-way analysis of variance, followed by appropriate post hoc analysis that corrected for the number of comparisons and unpaired $t$-tests (parametric), or a Kruskal-Wallis test, followed by $U$-tests (nonparametric). Investigators were blinded to the experimental groups (S.F.A, D.D., and D.M.T). A value of $P<0.05$ was considered significant. Data are expressed as means \pm SEM. 
A

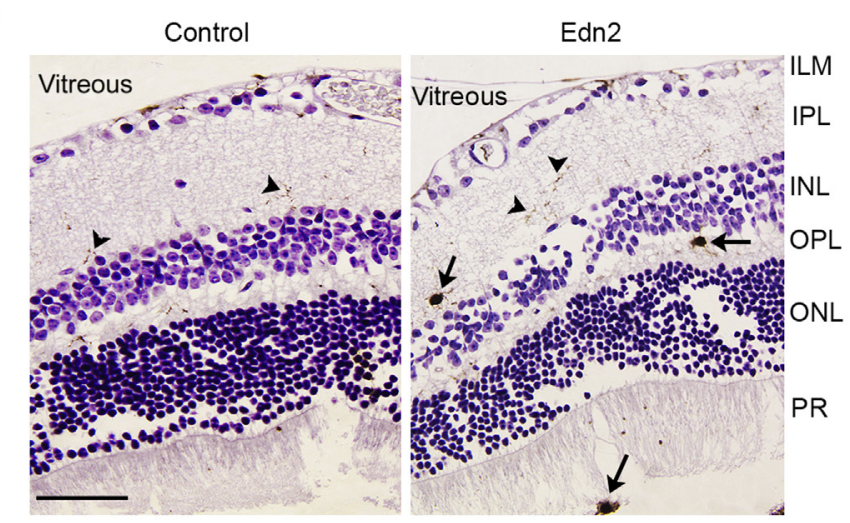

B

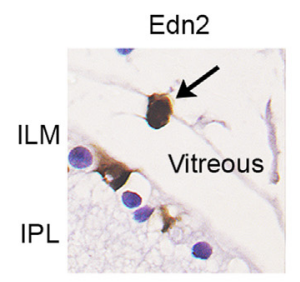

C

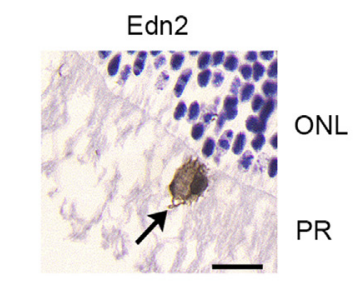

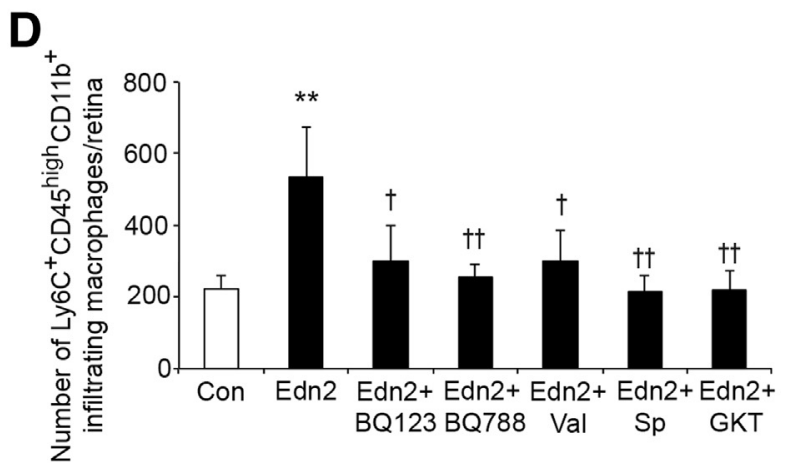

E
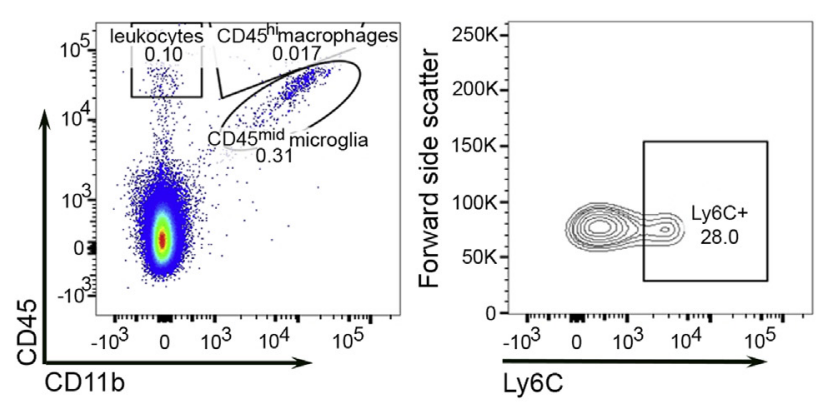

Figure 1 Infiltrating macrophages are increased in the retina of eyes administered endothelin-2 (Edn2). A: Representative images of 3- $\mu \mathrm{m}$ paraffin sections of retina immunolabeled with the microglia/macrophage marker ionized calcium binding adaptor molecule-1 (Iba1). Sparse Iba1 immunolabeling was detected in the ramified cell processes (arrowheads) of presumably microglia in eyes administered control vehicle or Edn2. B and C: Large amoeboid-shaped $\mathrm{Iba}^{+}$cells (arrows) were detected throughout the retina of eyes administered Edn2 and were present in the vitreous cavity (B) and photoreceptor layer (C). D and E: Flow cytometric analysis and gating strategy showing that the number of $\mathrm{Ly}_{6 \mathrm{C}} \mathrm{CD}^{+} 5^{\text {high }} \mathrm{CD} 11 \mathrm{~b}^{+}$infiltrating macrophages was increased in the eyes administered Edn2 compared with eyes receiving control vehicle. All treatments reduced the number of infiltrating macrophages. Data are expressed as means \pm SEM. $n=5$ to $7 \mathrm{C} 57 \mathrm{BL} / 6 \mathrm{~J}$ mice per group $(\mathbf{A}-\mathbf{C}) ; n=4$ to $5 \mathrm{C} 57 \mathrm{BL} / 6 \mathrm{~J}$ mice per group $(\mathbf{D}$ and $\mathbf{E}) .{ }^{* *} P<0.01$ versus control vehicle; ${ }^{\dagger} P<0.05$, ${ }^{\dagger} P<0.01$ versus Edn2. Scale bars: $65 \mu \mathrm{m}$ (A); $25 \mu \mathrm{m}$ (B and C). BQ123, Edn receptor type A blocker; BQ788, Edn receptor type B blocker; Con, control vehicle; GKT, NADPH oxidase 1/4 inhibitor; ILM, inner limiting membrane; INL, inner nuclear layer; IPL, inner plexiform layer; ONL, outer nuclear layer; OPL, outer plexiform layer; PR, photoreceptors; Sp, spironolactone; Val, valsartan.

\section{Results}

Body Weight Is Unaffected by Edn2 and the Treatments

After 4 weeks of treatment, the body weights of mice were similar between controls and Edn2-treated groups (control vehicle, $22.71 \pm 0.81 \mathrm{~g}$; Edn2, $23.47 \pm 0.97 \mathrm{~g}$ ). In Edn2-treated mice, the administration of the Agtr1 antagonist, valsartan $(22.16 \pm 1.83 \mathrm{~g})$, Mlr antagonist, spironolactone $(20.15 \pm 1.81$ g), Nox1/4 inhibitor, GKT137831 (19.92 $\pm 1.77 \mathrm{~g})$, Ednra antagonist, BQ123 (19.18 $\pm 1.71 \mathrm{~g})$, and Ednrb antagonist, BQ788 (19.37 $\pm 1.71 \mathrm{~g})$ did not influence body weight compared with controls and Edn2 alone-treated groups.

\section{Edn2 Promotes the Infiltration of Macrophages into the Retina}

The histopathology of the retina was first evaluated, and it was found that large amoeboid-shaped cells were present in eyes administered Edn2 but were absent from eyes administered control vehicle. Because Edn2 was reported to have chemokine properties, ${ }^{7}$ retinas were evaluated after immunolabeling with Iba1, which identified microglia resident in the retina as well as macrophages. ${ }^{37} \mathrm{Iba}^{+}$cells with long ramified processes that were phenotypically similar to microglia ${ }^{38}$ were sparse in retina from eyes administered control vehicle or Edn2 (Figure 1A). However, the prominent feature in the retinas of Edn2-treated mice was large amoeboid-shaped $\mathrm{Iba}^{+}$cells reminiscent of macrophages. These Iba $1^{+}$cells were present not only in the retina but also in the vitreous cavity exterior to the inner surface of the retina and in the outer retina near the photoreceptors and RPE/choroid (Figure 1, A-C), suggesting that they were infiltrating immune cells. To further investigate these findings flow cytometry was performed, and it was found that Edn2 increased the number of infiltrating macrophages, which were $\mathrm{Ly} 6 \mathrm{C}^{+} \mathrm{CD} 45^{\text {high }} \mathrm{CD} 11 \mathrm{~b}^{+}$ cells (Figure 1, D and E). To evaluate if the RAAS and Nox pathways influenced the Edn2-mediated increase in infiltrating macrophages, mice were co-administered with intraperitoneal injection inhibitors of the Agtr1, Mlr, or 


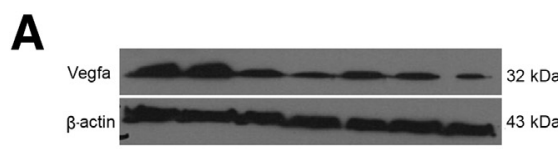

B

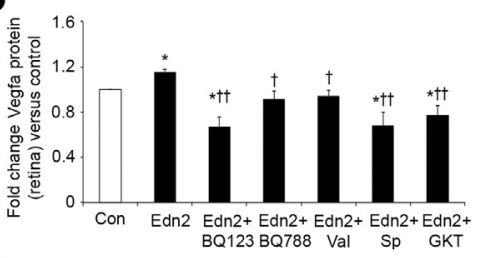

D
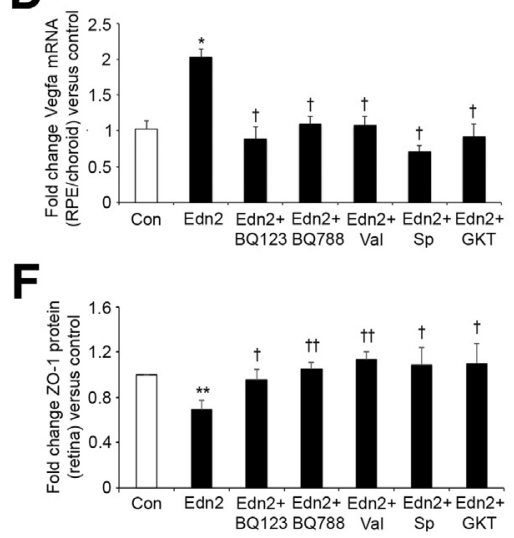

H

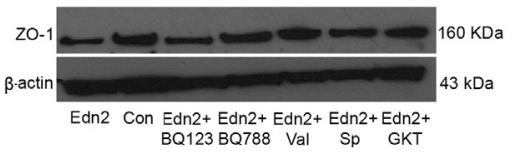

C

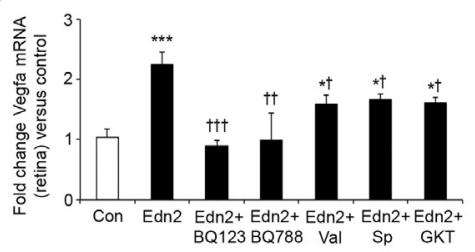

E

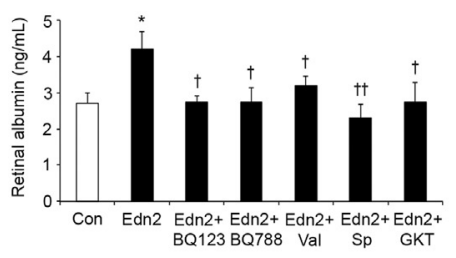

G

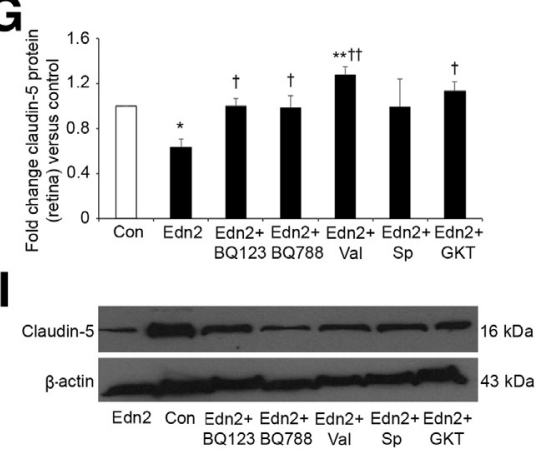

Figure 2 Vascular endothelial growth factor (Vegfa) and vascular permeability were increased in the retina of eyes administered endothelin-2 (Edn2). A-E: The intravitreal administration of Edn2 increased Vegfa protein levels in retina (A and $\mathbf{B})$, Vegfa mRNA levels in retina (C), Vegfa mRNA levels in retinal pigment epithelium (RPE)/ choroid (D), and vascular leakage in retina (E) compared with controls, which were reduced by all treatments. F-I: Edn2 reduced the protein levels of zona occludin-1 (Z0-1) (F and $\mathbf{H}$ ) and claudin-5 ( $\mathbf{G}$ and $\mathbf{I})$, which was prevented by all treatments. Edn2 reduced the protein levels of claudin-5, which was prevented by the treatments except spironolactone (Sp). mRNA levels were measured by real-time quantitative PCR. Vascular leakage was measured by enzyme-linked immunosorbent assay. Vegfa, Z0-1, and claudin- 5 protein levels were measured by Western blot analysis. Data are expressed as means \pm SEM. $n=4$ to 7 C57BL/6] mice per group to measure mRNA levels; $n=4$ to $6 \mathrm{C} 57 \mathrm{BL} / 6 \mathrm{~J}$ mice per group to measure vascular leakage and to measure protein levels. ${ }^{*} P<0.05$, $* * P<0.01$, and $* * * P<0.001$ versus control vehicle; ${ }^{\dagger} P<0.05,{ }^{\dagger \dagger} P<0.01$, and ${ }^{\dagger \dagger \dagger} P<0.001$ versus Edn2. BQ123, Edn receptor type A blocker; BQ788, Edn receptor type B blocker; Con, control vehicle; Edn2, endothelin-2; GKT, NADPH oxidase $1 / 4$ inhibitor; Val, valsartan.
Nox1/4. All of these treatments reduced the number of infiltrating macrophages in the retina (Figure 1, D and E).

\section{Edn2 Promotes Vascular Injury in the Retina}

We postulated that the Edn2-induced influx of macrophages into the retina and near the RPE/choroid was associated with breakdown of the vasculature at these sites. Therefore, the expression of the potent vascular permeability factor, Vegfa, was evaluated. ${ }^{17}$ Edn2 increased Vegfa mRNA and Vegfa protein levels in the retina, as well as Vegfa mRNA levels in the RPE/choroid compared with eyes administered control vehicle, and all treatments reduced Vegfa levels (Figure 2, A-D). Next, vascular leakage was evaluated in the retina, but not the RPE/choroid because of the small amount of tissue available, and it was found that Edn2 increased retinal vascular leakage by 1.5 -fold compared with eyes administered control vehicle (Figure 2E). All treatments prevented vascular leakage in the retina (Figure 2E). Tight junctional proteins influenced the integrity of the inner retinal $\mathrm{BRB}^{39}$ and subsequently vascular leakage. Edn2 reduced the protein levels of ZO-1 and claudin-5 in retinas (Figure 2, $\mathrm{F}-\mathrm{I})$. All of the treatments prevented the reduction in ZO-1 levels and, except for spironolactone, prevented the reduction in claudin-5 in retinas (Figure 2, F-I).

\section{Edn2 Damages Retinal Müller Cells}

Gfap is an intermediate filament protein that in healthy retina is expressed by astrocytes at the surface of the retina, ${ }^{14}$ as observed in eyes administered control vehicle (Figure 3A). However, when the retina, including the vasculature, becomes damaged, Müller cells may react by expressing increased amounts of Gfap. ${ }^{14}$ In eyes administered Edn2, Gfap immunolabeling was increased compared with controls and was now distributed in the cell processes of Müller cells that extended across the retina (Figure 3A). All treatments reduced the Edn2-mediated increase in Gfap immunolabeling, albeit not to the level of controls (Figure 3, $\mathrm{A}$ and $\mathrm{B}$ ). To further interrogate Gfap expression qPCR was performed, which showed an increase in Gfap mRNA levels in eyes administered Edn2 compared with controls, which was reduced by all treatments, and with BQ123 and BQ788 this attenuation of Gfap expression was to the level of controls (Figure 3C).

\section{Edn2 Increases the Expression of Ion and Water Channels in the Retina}

In response to damage to the retina, disturbances in ion and water may occur in Müller cells, which involve alterations in 
A

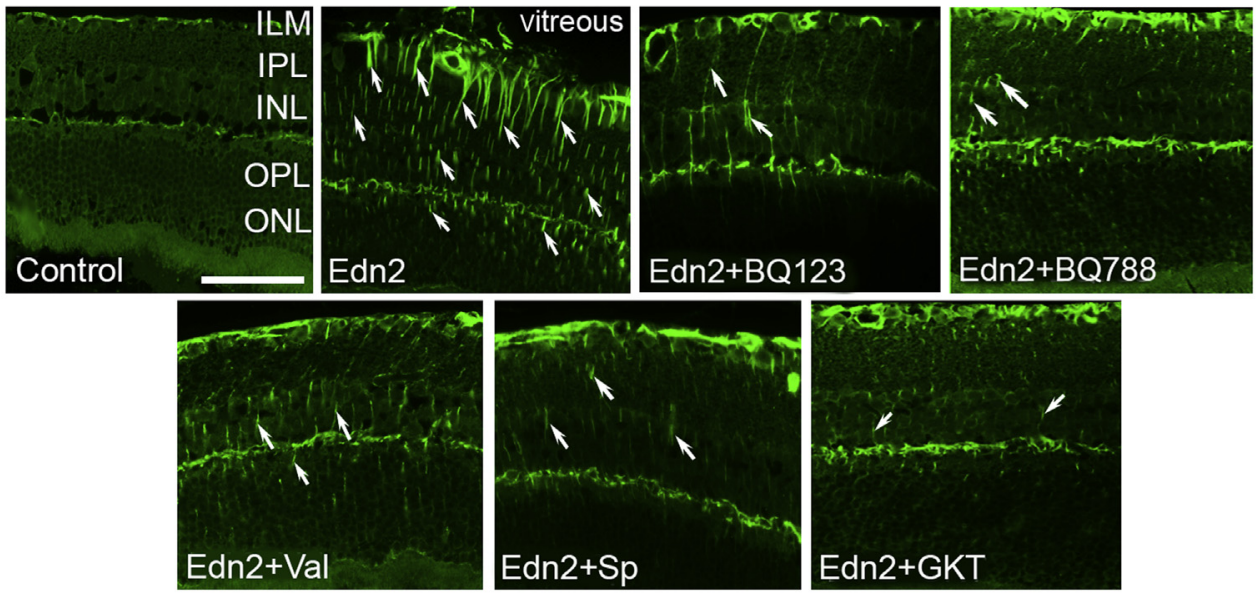

B

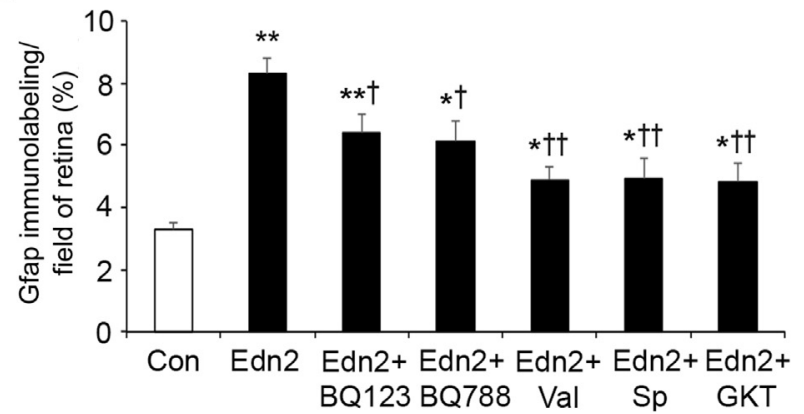

C

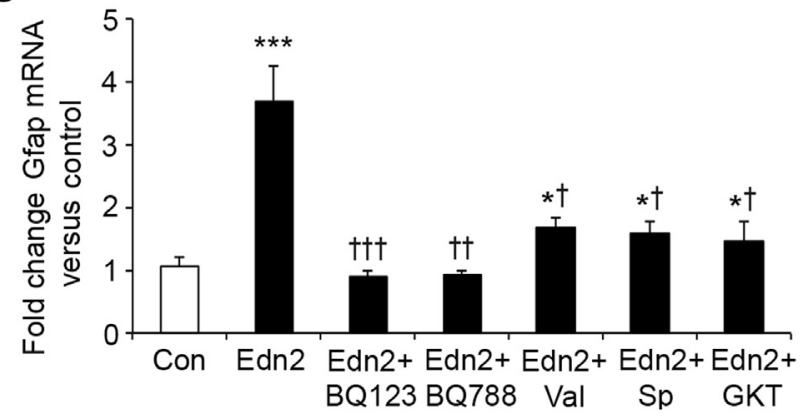

Figure 3 Glial fibrillary acidic protein (Gfap) increased in the retina of eyes administered endothelin-2 (Edn2). A: Representative images of 3- $\mu \mathrm{m}$ paraffin sections of retina. Gfap immunolabeling (arrows) was sparse in controls but increased in Müller cell processes in eyes administered Edn2. All treatments reduced Gfap immunolabeling. B: Quantitation of Gfap immunolabeling was performed from the inner limiting membrane (ILM) to the outer nuclear layer (ONL). C: Gfap mRNA levels (real-time quantitative PCR) were increased by Edn2 and reduced by all of the treatments. Data are expressed as means \pm SEM. $n=5$ to $7 \mathrm{C} 57 \mathrm{BL} / 6 \mathrm{~J}$ mice per group (B); $n=4$ to $7 \mathrm{C} 57 \mathrm{BL} / 6 \mathrm{~J}$ mice per group (C). ${ }^{*} P<0.05$, ${ }^{*} P<0.01$, and ${ }^{* *}{ }^{*} P<0.001$ versus control vehicle; ${ }^{\dagger} P<0.05,{ }^{\dagger \dagger} P<0.01$, and ${ }^{\dagger \dagger} P<0.001$ versus Edn2. Scale bar $=80 \mu \mathrm{m}$. BQ123, Edn receptor type A blocker; BQ788, Edn receptor type B blocker; Con, control vehicle; GKT, NADPH oxidase 1/4 inhibitor; INL, inner nuclear layer; IPL, inner plexiform layer; OPL, outer plexiform layer; Val, valsartan; Sp, spironolactone.

water channels, including Aqp4, and potassium channels such as Kir4.1. ${ }^{40}$ Thus, the expression of Aqp4 and Kir4.1 was evaluated in retinas by using immunohistochemistry and qPCR. In eyes administered control vehicle, Aqp4 and Kir4.1 immunolabeling was sparse in the retina, but in eyes administered Edn2, Aqp4 (Figure 4, A and B) and Kir4.1 (Figure 5, A and B) immunolabeling for both proteins was increased in the cell processes of Müller cells. All treatments reduced the Edn2-mediated increase in Aqp4 and Kir4.1 immunolabeling (Figure 4, C and D, and Figure 5, C and D) in retina as well as Aqp4 and Kir4.1 mRNA levels, which for BQ123 and BQ788 was reduced to control levels (Figures 4E and 5E).

\section{Edn2 Damages Cultured Müller Cells}

In some situations, Müller cells may themselves become damaged. ${ }^{14,41,42}$ To determine whether the effect of Edn2 was direct cultured Müller cells were studied. The actions of Edn2 have been linked to the mitogen-activated protein kinase/ERK1/2 pathway. ${ }^{7}$ In primary cultures of rat Müller cells, Edn2 increased the phosphorylation of ERK1/2, which was reduced by BQ123 and BQ788 (Figure 6, A and B). It was next evaluated if the effects of Edn2 on Müller cells that were observed in vivo occurred in vitro. Indeed, in cultured Müller cells, Edn2 increased the mRNA levels of Vegfa, Gfap, Aqp4, and Kir4.1, all of which were reduced to control levels by BQ123, BQ788, valsartan, spironolactone, and GKT137831 (Figure 6, C-F). Because in vivo Edn2 promoted macrophage infiltration, we hypothesized that this may relate to a direct effect of the chemokine, Mcp1. Edn2 induced the up-regulation of Mcp1 by Müller cells as reflected by increased Mcp1 protein levels in cell supernatant (Figure 6G). Furthermore, all inhibitors abrogated the increase in Mcp1 protein induced by Edn2 in Müller cells (Figure 6G).

Ang II, Aldosterone, and ROS Influence Edn2-Mediated Effects in Müller Cells

These findings indicated that blockade of Ang II or aldosterone reduced the detrimental effects of Edn2 on Müller cells. To interrogate this further, primary cultures of Müller 
A

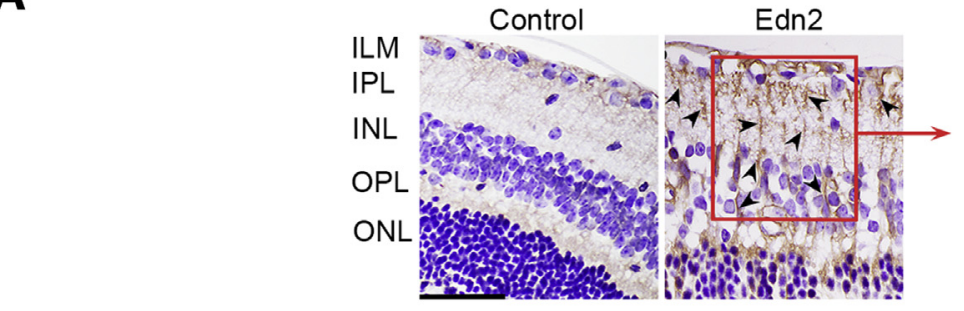

B

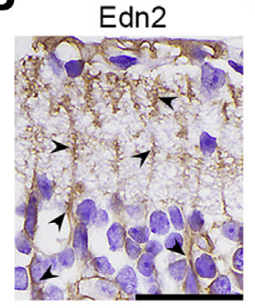

C

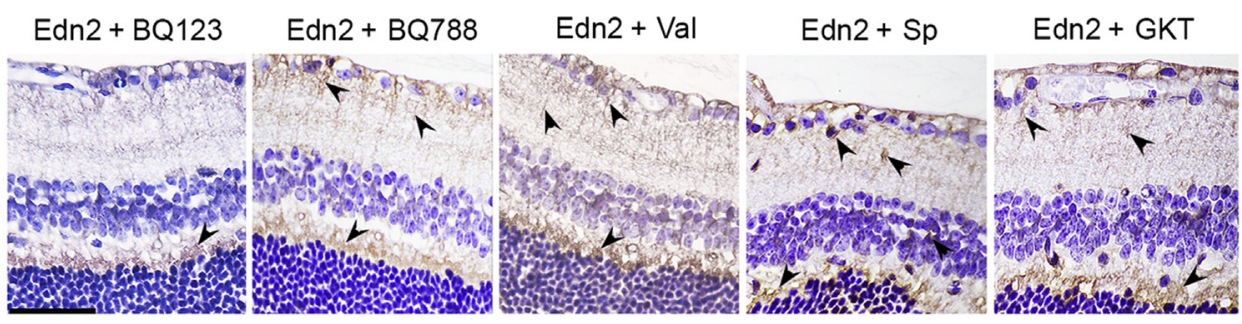

D

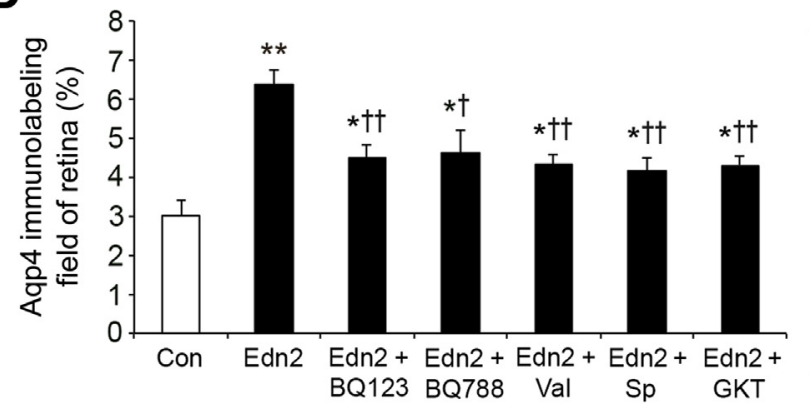

E

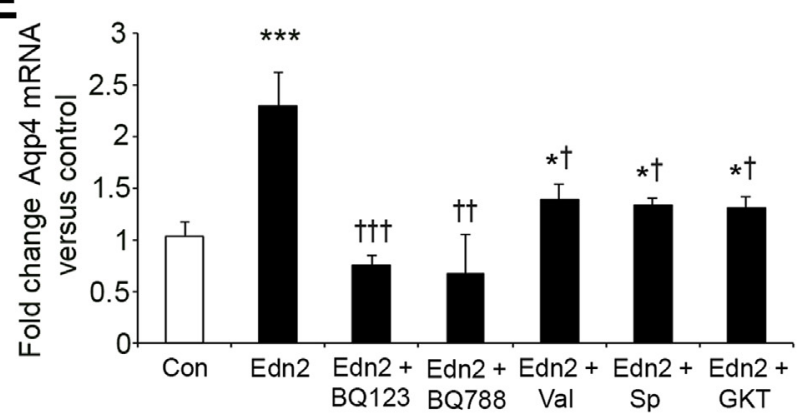

Figure 4 Aquaporin-4 (Aqp4) increased in the retina of eyes administered endothelin-2 (Edn2). A-C: Representative images of 3- $\mu \mathrm{m}$ paraffin sections of retina. B: High-powered image of Edn2 group in A. Aqp4 immunolabeling (arrowheads in $\mathbf{A}-\mathbf{C}$ ) was sparse in controls, but was increased in Müller cell processes in eyes administered Edn2. All treatments reduced Aqp4 immunolabeling. D: Quantitation of Aqp4 immunolabeling was performed from the inner limiting membrane (ILM) to the outer nuclear layer (ONL). E: Aqp4 mRNA levels (real-time quantitative PCR) were increased by Edn2 and reduced by all treatments. Data are expressed as means \pm SEM. $n=5$ to 7 C57BL/6J mice per group (D); $n=4$ to $7 \mathrm{C} 57 \mathrm{BL} / 6 \mathrm{~J}$ mice per group (E). ${ }^{*} P<0.05,{ }^{* *} P<0.01$, and ${ }^{* * * P}<0.001$ versus control vehicle; ${ }^{\dagger} P<0.05,{ }^{\dagger \dagger} P<0.01$, and ${ }^{\dagger \dagger} P<0.001$ versus Edn2. Scale bars: $85 \mu \mathrm{m}$ (A and C); $45 \mu \mathrm{m}$ (B). BQ123, Edn receptor type A blocker; BQ788, Edn receptor type B blocker; Con, control vehicle; GKT, NADPH oxidase 1/4 inhibitor; INL, inner nuclear layer; IPL, inner plexiform layer; $\mathrm{OPL}$, outer plexiform layer; Val, valsartan; Sp, spironolactone.

cells were studied, and it was also evaluated if ROS was involved. In Müller cells, Ang II and aldosterone increased the expression of Edn2 (Figure 7A), and co-administration of inhibitors of ROS (diphenyliodonium or N-acetylcysteine) or Nox $1 / 4$ reduced the Ang II- and aldosteronemediated increase in Edn2 mRNA levels (Figure 7A). It was next evaluated if Edn2 influenced Nox and ROS, and if this involved the RAAS. Edn2 increased the mRNA levels of Nox1, Nox2, and Nox4 (Figure 7B). Further, Edn2 increased ROS levels in retinal Müller cells compared with controls, which was reduced by BQ123, BQ788, valsartan, spironolactone, and GKT137831 (Figure 7, C and D).

\section{Discussion}

A major cause of vision loss and blindness is disruption of the BRB and retinal edema, pathology that is highly influenced by macroglial Müller cells. ${ }^{14,40}$ The findings of this study indicated that Edn2 promoted this retinal pathology independently of any systemic effects of Edn2 on blood pressure. Specifically, the intraocular administration of Edn2 compromised the BRB with increased vascular leakage and reduced expression of tight junctional barrier proteins as well as the infiltration of macrophages into the retina. Further, macroglial Müller cells exhibited marked gliosis, increased expression of Vegfa, as well as water and ion transporters. These pathogenic effects of Edn2 involved both the Ednra and Ednrb, with individual receptor blockade similarly protective in the retina and Müller cells. In the context that blockade of the Agtr1 and Mlr are well validated strategies for the treatment of a variety of retinopathies, ${ }^{24,25,43,44}$ our data demonstrated that the beneficial effects of these approaches are likely to extend to Edn2mediated breakdown of the BRB and Müller cells dysfunction. The in vitro data indicated that Edn2 directly injured Müller cells, which involved ROS, including ROS derived from Nox1/4, and that both Ang II and aldosterone 
A
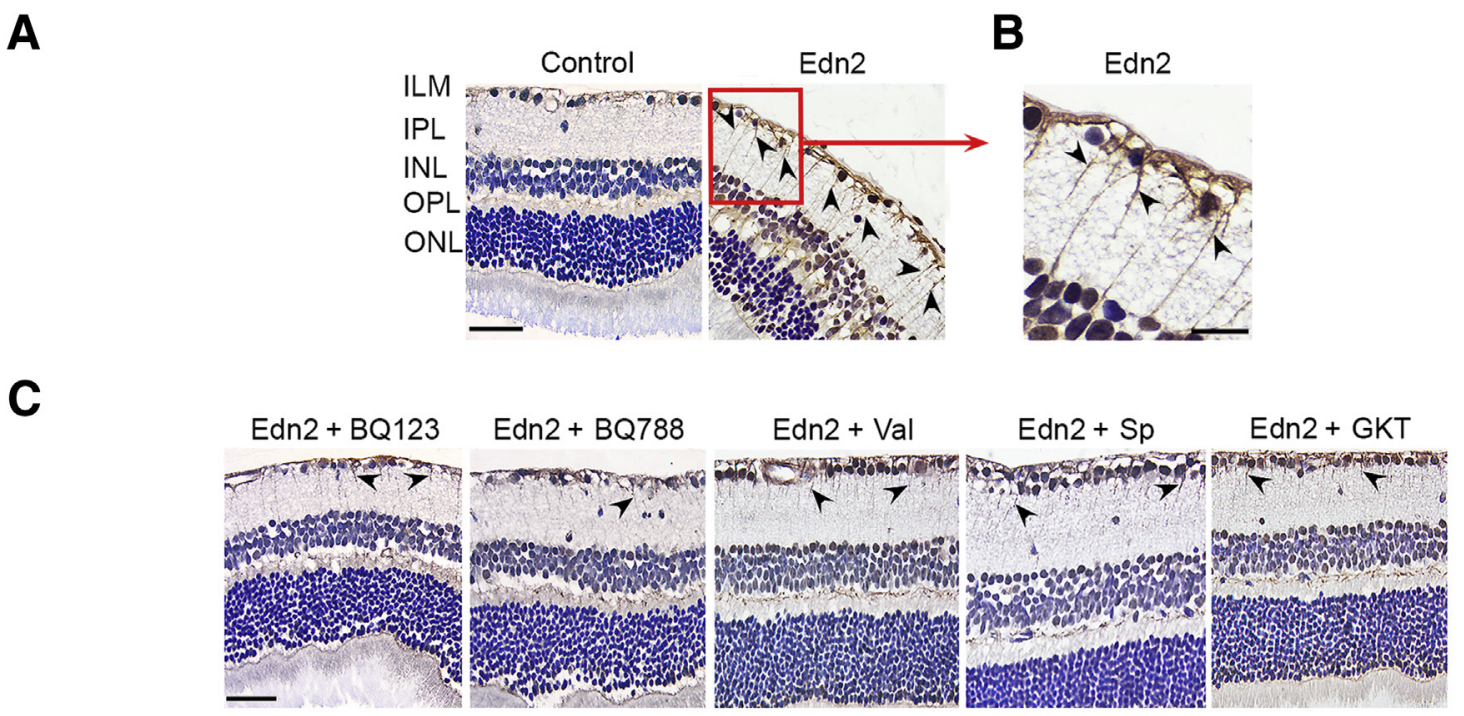

D

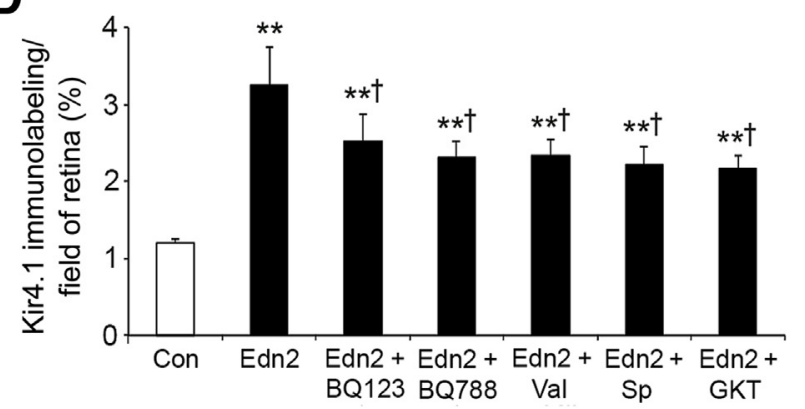

$\mathbf{E}$

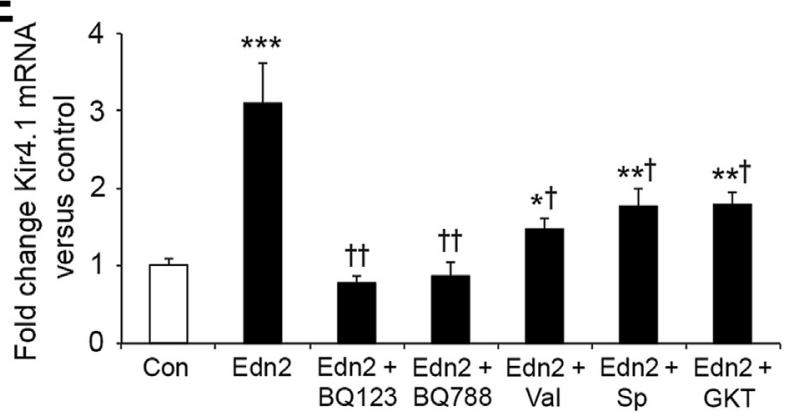

Figure 5 Kir4.1 increased in the retina of eyes administered endothelin-2 (Edn2). A-C: Representative images of 3- $\mu \mathrm{m}$ paraffin sections of retina. B: High-powered image of Edn2 group in A. Kir4.1 immunolabeling was sparse in controls but was increased in Müller cell endfeet on the surface of the retina as well as Müller cell processes (arrowheads in A-C) in eye administered Edn2. D: Quantitation of Kir4.1 immunolabeling was performed from the inner limiting membrane (ILM) to the outer nuclear layer (ONL). E: Kir4.1 mRNA levels (real-time quantitative PCR) was increased by Edn2 and reduced by all treatments. Data are expressed as means \pm SEM. $n=5$ to 7 C57BL/6J mice per group (D); $n=4$ to 7 C57BL/6J mice per group (E). ${ }^{*} P<0.05,{ }^{* *} P<0.01$, and ${ }^{* * *} P<0.001$ versus control vehicle; ${ }^{\dagger} P<0.05,{ }^{\dagger} P<0.01$ versus Edn2. Scale bars: $60 \mu \mathrm{m}$ (A and C); $30 \mu \mathrm{m}$ (B). BQ123, Edn receptor type A blocker; BQ788, Edn receptor type B blocker; Con, control vehicle; GKT, NADPH oxidase 1/4 inhibitor; INL, inner nuclear layer; IPL, inner plexiform layer; OPL, outer plexiform layer; Val, valsartan; Sp, spironolactone.

influenced these events. These findings revealed a potentially important mechanism that linked Edn2, the RAAS, and Nox pathways in promoting injury to a particular cell population, the Müller cell, which is central to maintaining retinal health. ${ }^{14}$

A striking finding was the increased presence of large amoeboid-shaped $\mathrm{Iba}^{+}$cells in the retina and vitreous cavity of eyes administered Edn2, which were identified as infiltrating macrophages and absent from eyes injected with control vehicle. These data are consistent with previous in vitro studies that $\mathrm{Edn} 2$ has chemoattractant properties and exerts as strong a response as the potent chemokine (C-C motif) ligand 2/Mcp1 for macrophages. ${ }^{7}$ Studies of macrophages and monocytic cells have attributed the chemokine actions of Edn2 to the Ednrb. ${ }^{7}$ The finding that antagonism of the Ednra (BQ123) or Ednrb (BQ788) reduced Edn2induced trafficking of macrophages into the retina is consistent with both Edn receptors having a role in the chemokine properties of Edn2. Moreover, the capacity of Edn2 to increase the secretion of Mcp1 from cultured Müller cells, which was inhibited by BQ123 and BQ788, indicated that Edn2 may not only be a chemoattractant per se but may also promote macrophage infiltration indirectly by increasing retinal Mcp1 levels. Overall, these data are consistent with the emerging view that Edn2 is a proinflammatory mediator, including within the retina. ${ }^{1}$

The ability of Edn2 to induce the influx of macrophages into the retina suggested that Edn2 had compromised the $\mathrm{BRB}$, which was reflected by increased retinal vascular leakage and a reduction in ZO-1 and claudin-5, proteins that are necessary to maintain the properties of the inner retinal BRB. ${ }^{39,45}$ Furthermore, Edn2 increased the levels of Vegfa in the retina and RPE/choroid. The excess production of Vegfa by RPE cells and Müller cells contributes to vascular pathology, including increased vascular permeability. ${ }^{14,16,46}$ Indeed, Müller cells influence the barrier properties of the 


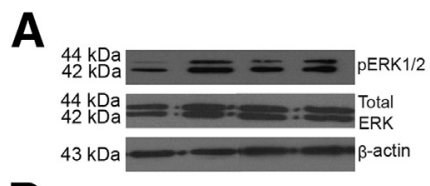

B

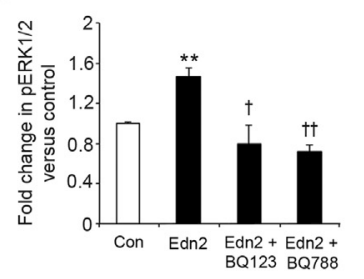

D

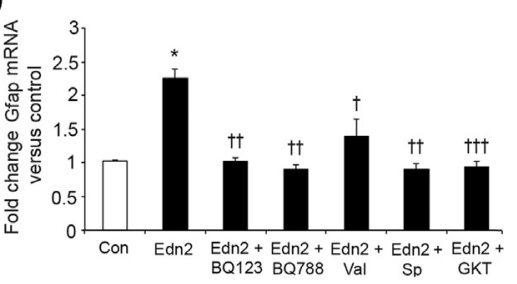

$\mathbf{F}$

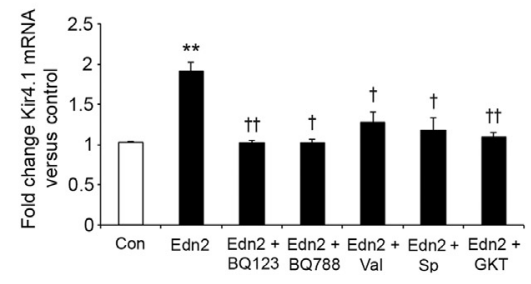

C

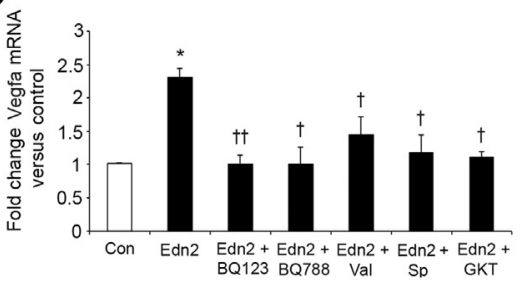

E

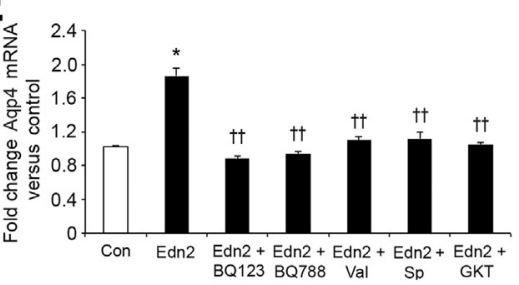

G

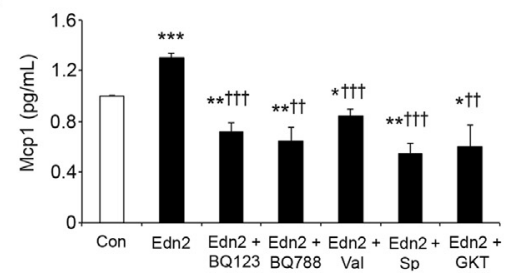

Figure 6 The response of cultured Müller cells to endothelin-2 (Edn2). Experiments were performed in primary cultures of rat Müller cells. A and B: Edn2 increased the phosphorylation of extracellular-signal-regulated kinase 1/2 (pERK1/ $2)$, which was reduced by Edn receptor type $A$ (B0123) and Edn receptor type B (B0788). C-G: Edn2 increased the mRNA levels of vascular endothelial growth factor (Vegfa; C), glial fibrillary acidic protein (Gfap; D), aquaporin-4 (Aqp4; E), and Kir4.1 (F) in Müller cells as well as the protein levels of monocyte chemoattractant protein-1 (Mcp1; G) in cell supernatant. Data are expressed as means \pm SEM. $n=3$ independent experiments with 3 samples within each experiment. ${ }^{*} P<0.05$, $* * P<0.01$, and $* * * P<0.001$ versus control vehicle; ${ }^{\dagger} P<0.05,{ }^{\dagger} P<0.01$, and ${ }^{\dagger \dagger} P<0.001$ versus Edn2. Con, control vehicle; GKT, NADPH oxidase 1/4 inhibitor; Sp, spironolactone; Val, valsartan.
BRB because of their cell processes ensheathing retinal capillaries. $^{14}$ In disease, the biomechanical properties of Müller cells become weakened and gliotic because of the stiffening of cell processes from an increase in the expression of the intermediate filament, Gfap. The finding that in vivo Edn2 increased Gfap expression in the retina, and both Gfap and Vegfa were reduced by blockade of the Ednra or Ednrb, indicated that Edn2 has potent effects on Müller cells and the vasculature. However, because Edn2 has vasoconstrictor properties, ${ }^{47}$ it is possible that the influence of Edn2 on Müller cells in vivo is secondary to its vasoactive actions on the retinal vasculature. To address this possibility, Edn2 was locally administered into the eye, but this approach may have influenced local retinal blood flow. By investigating primary cultures of Müller cells in which any contribution from vasoconstriction cannot occur, it was shown that Edn2 directly stimulated an increase in Gfap, a finding that is in agreement with a study in a rat Müller cell line, ${ }^{48}$ and also increased the production and secretion of Vegfa. The actions of Edn2 in various tissues have been attributed to its binding to one or both of its receptors. ${ }^{7,11}$ Müller cells express both Ednra and Endrb, ${ }^{18}$ and we demonstrated that Edn2's stimulation of Müller cell pathology may be attenuated by antagonism of either of these receptors.
The ability of Müller cells to prevent vision-threatening retinal edema occurs by their promotion of trans-retinal fluid movement through water channels such as Aqp4, as well as the siphoning of excess potassium into blood vessels or the vitreous cavity through potassium channels such as Kir4.1. ${ }^{40}$ The expression of Aqp4 and Kir4.1 are altered in some retinal diseases to prevent cell swelling. ${ }^{40}$ In vivo, Edn2 increased Aqp4 and Kir4.1 immunolabeling in Müller cells and their mRNA levels in the retina. This increase was confirmed in cultured Müller cells in which antagonism of either the Ednra or Ednrb attenuated the increase in both Aqp4 and Kir4.1. These data differ somewhat from a previous study in which isolated Müller cell somata exposed to a hypo-osmotic environment resulted in cell swelling that was rescued by Edn2. ${ }^{18}$ The reasons for the differences between the two studies are not entirely clear but may relate to the experimental conditions. ${ }^{18}$

The factors that regulate the actions of Edn2 in the retina have not been extensively investigated and to date include tissue hypoxia ${ }^{49}$ and the retinal signaling molecule Norrin. ${ }^{50}$ Studies of the cardiovascular system and kidney have revealed considerable cross talk between Edn1 and the RAAS. ${ }^{19}$ The data suggest that similar interactions occur in the retina with respect to Edn2, with inhibition of the Agtr1 or Mlr, receptors that are expressed in a variety of retinal 
A

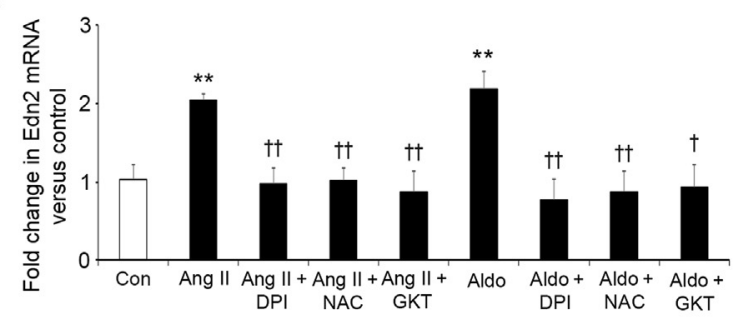

C

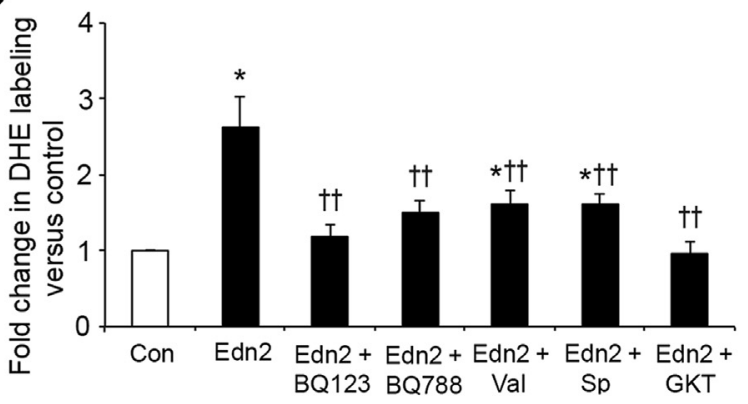

B

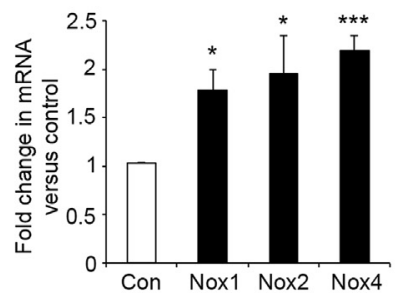

D

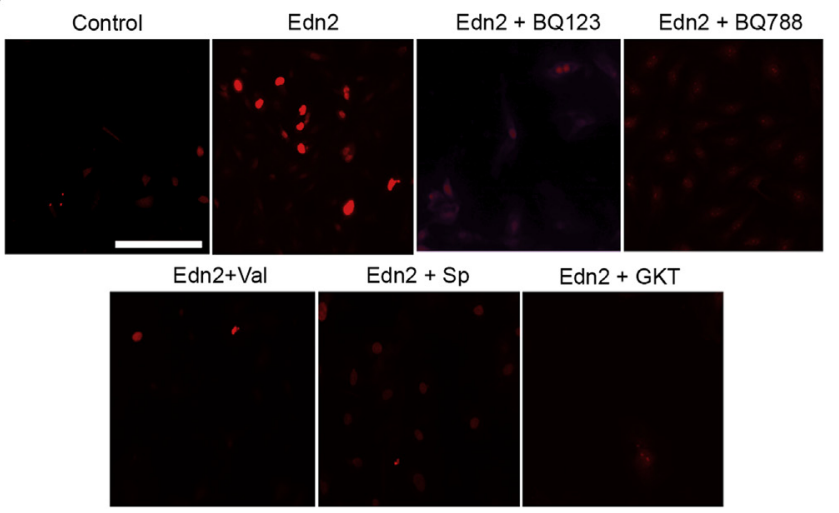

Figure 7 Interactions between endothelin-2 (Edn2), angiotensin II (Ang II), aldosterone (Aldo), and reactive oxygen species (ROS) in cultured Müller cells. Experiments were performed in primary cultures of rat Müller cells. A and B: Quantitation of Edn2 (A) and NADPH oxidase (Nox; B) mRNA levels by using real-time quantitative PCR. C: Quantitation of ROS levels by using dihydroethidium (DHE) labeling. D: Representative micrographs of retinal Müller cells labeled with DHE to detect ROS. Data are expressed as means \pm SEM. $n=3$ independent experiments with 3 samples within each experiment. ${ }^{*} P<0.05, * * P<0.01$, and ${ }^{* * *} P<0.001$ versus control vehicle; ${ }^{\dagger} P<0.05,{ }^{\dagger \dagger} P<0.01$ versus Edn2. Scale bar $=45 \mu \mathrm{m}$. BQ123, Edn receptor type A blocker; BQ788, Edn receptor type B blocker; Con, control vehicle; DPI, diphenyliodonium; GKT, Nox1/4 inhibitor; NAC, N-acetylcysteine; Sp, spironolactone; Val, valsartan.

cells, including Müller cells, ${ }^{24,51}$ are similarly effective approaches as Edn receptor blockade in reducing Edn2induced retinopathy. These findings are likely to be relevant to retinopathies in which Edn2 levels are elevated ${ }^{12,13}$ and may extend the benefits of RAAS blockade as treatments for patients with diabetic retinopathy ${ }^{52,53}$ and chorioretinopathy. ${ }^{44}$ It is possible that Edn2 directly stimulated the production of Ang II and aldosterone as has been shown for Edn1 in other tissues. ${ }^{54,55}$ A limitation of this study is that these hormones were not measured because of the technical difficulty in accurately measuring Ang II and aldosterone in a small tissue such as the retina or in Müller cells. In addition, Ang II and aldosterone may increase the synthesis of Edns, ${ }^{20,56}$ and the data indicate that this may occur in retinal Müller cells in the context of Edn2. Of interest in future studies is whether retinal astrocytes, which also contribute to the BRB,${ }^{57}$ are involved in Edn2-mediated pathology in the retina.

The excessive production of ROS derived from Nox has emerged as a causal factor in a variety of diseases, including retinopathies ${ }^{33,34,58,59}$ The actions of Edn1, Ang II, and aldosterone have been attributed at least in part to the increased generation of ROS. ${ }^{60,61}$ Here, we identified that in Müller cells the cross talk among Edn2, the RAAS, and Nox involves ROS. First, general ROS inhibitors (diphenyliodonium and $\mathrm{N}$-acetylcysteine) reduced Ang II and aldosterone's stimulation of Edn2 expression. Second, Edn2 increased the expression of Nox isoforms and ROS levels, which was reduced by agents that inhibit all of the studied pathways. The finding that specific Nox1/4 inhibition reduced Edn2-induced ROS levels is of interest because this approach has previously been shown to reduce retinal vascular leakage and Müller cell damage, ${ }^{33}$ and it also has

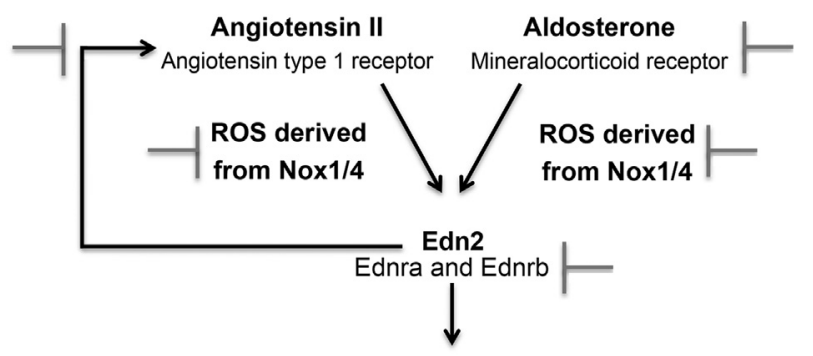

Müller cell dysfunction and breakdown of the blood-retinal barrier

Figure 8 Scheme showing the proposed mechanisms by which endothelin-2 (Edn2) influences retinal disease. Angiotensin II and aldosterone stimulate Edn2 expression, which by the production of reactive oxygen species (ROS) and the Edn receptor type A (Ednra) and Edn receptor type $B$ (Ednrb) promote Müller cell dysfunction and breakdown of the blood-retinal barrier. Edn2 may increase the production of angiotensin II and aldosterone to elicit retinal pathology by their cognate receptors. Inhibition of Edn2-mediated retinopathy is reduced by inhibition of the angiotensin type 1 receptor, mineralocorticoid receptor, or ROS, including ROS derived from NADPH oxidase (Nox)1/4. 
beneficial effects in other diseases such as diabetic nephropathy $^{62}$ and liver fibrosis. ${ }^{63}$

\section{Conclusions}

Edn2 promoted vision-threatening pathology, including vascular leakage, inflammation, and damage to retinal Müller cells. Our data highlighted that interactions among Edn2, the RAAS, and ROS/Nox systems should be considered (Figure 8) when developing effective treatment approaches for retinopathies in which disturbances in these vasoactive systems exist and appear to play a deleterious role in their progression.

\section{Acknowledgments}

We thank David R. Berka for technical assistance.

S.F.A., D.D., and D.M.T. performed the experiments; S.F.A., D.D., and J.L.W.-B. designed the experiments; J.L.W.-B. wrote the manuscript and generated the figures.

\section{References}

1. Ling L, Maguire JJ, Davenport AP: Endothelin-2, the forgotten isoform: emerging role in the cardiovascular system, ovarian development, immunology and cancer. Br J Pharmacol 2013, 168:283-295

2. Yanagisawa M, Kurihara H, Kimura S, Tomobe Y, Kobayashi M, Mitsui Y, Yazaki Y, Goto K, Masaki T: A novel potent vasoconstrictor peptide produced by vascular endothelial cells. Nature 1988 , 332:411-415

3. Polak K, Luksch A, Frank B, Jandrasits K, Polska E, Schmetterer L: Regulation of human retinal blood flow by endothelin-1. Exp Eye Res 2003, 76:633-640

4. Takei K, Sato T, Nonoyama T, Miyauchi T, Goto K, Hommura S: A new model of transient complete obstruction of retinal vessels induced by endothelin-1 injection into the posterior vitreous body in rabbits. Graefes Arch Clin Exp Ophthalmol 1993, 231:476-481

5. Takagi C, Bursell SE, Lin YW, Takagi H, Duh E, Jiang Z, Clermont AC, King GL: Regulation of retinal hemodynamics in diabetic rats by increased expression and action of endothelin-1. Invest Ophthalmol Vis Sci 1996, 37:2504-2518

6. Bagnato A, Loizidou M, Pflug BR, Curwen J, Growcott J: Role of the endothelin axis and its antagonists in the treatment of cancer. $\mathrm{Br} \mathrm{J}$ Pharmacol 2011, 163:220-233

7. Grimshaw MJ, Wilson JL, Balkwill FR: Endothelin-2 is a macrophage chemoattractant: implications for macrophage distribution in tumors. Eur J Immunol 2002, 32:2393-2400

8. Speciale L, Roda K, Saresella M, Taramelli D, Ferrante P: Different endothelins stimulate cytokine production by peritoneal macrophages and microglial cell line. Immunology 1998, 93:109-114

9. Plusczyk T, Bersal B, Menger MD, Feifel G: Differential effects of ET-1, ET-2, and ET-3 on pancreatic microcirculation, tissue integrity, and inflammation. Dig Dis Sci 2001, 46:1343-1351

10. Klipper E, Levit A, Mastich Y, Berisha B, Schams D, Meidan R: Induction of endothelin-2 expression by luteinizing hormone and hypoxia: possible role in bovine corpus luteum formation. Endocrinology 2010, 151:1914-1922

11. Filipovich T, Fleisher-Berkovich S: Regulation of glial inflammatory mediators synthesis: possible role of endothelins. Peptides 2008, 29: $2250-2256$
12. Patel C, Narayanan SP, Zhang W, Xu Z, Sukumari-Ramesh S, Dhandapani KM, Caldwell RW, Caldwell RB: Activation of the endothelin system mediates pathological angiogenesis during ischemic retinopathy. Am J Pathol 2014, 184:3040-3051

13. Binz N, Rakoczy EP, Ali Rahman IS, Vagaja NN, Lai CM: Biomarkers for diabetic retinopathy: could endothelin 2 be part of the answer? PLoS One 2016, 11:e0160442

14. Bringmann A, Pannicke T, Grosche J, Francke M, Wiedemann P, Skatchkov SN, Osborne NN, Reichenbach A: Muller cells in the healthy and diseased retina. Prog Retin Eye Res 2006, 25:397-424

15. Tout S, Chan-Ling T, Hollander H, Stone J: The role of Muller cells in the formation of the blood-retinal barrier. Neuroscience 1993, 55: 291-301

16. Bai Y, Ma JX, Guo J, Wang J, Zhu M, Chen Y, Le YZ: Muller cellderived VEGF is a significant contributor to retinal neovascularization. J Pathol 2009, 219:446-454

17. Aiello LP, Bursell SE, Clermont A, Duh E, Ishii H, Takagi C, Mori F, Ciulla TA, Ways K, Jirousek M, Smith LE, King GL: Vascular endothelial growth factor-induced retinal permeability is mediated by protein kinase $\mathrm{C}$ in vivo and suppressed by an orally effective betaisoform-selective inhibitor. Diabetes 1997, 46:1473-1480

18. Vogler S, Grosche A, Pannicke T, Wiedemann P, Reichenbach A, Bringmann A: Endothelins inhibit osmotic swelling of rat retinal glial and bipolar cells by activation of growth factor signaling. Neurochem Res 2016, 41:2598-2606

19. Komers R, Plotkin H: Dual inhibition of renin-angiotensinaldosterone system and endothelin-1 in treatment of chronic kidney disease. Am J Physiol Regul Integr Comp Physiol 2016, 310: R877-R884

20. Emori T, Hirata Y, Ohta K, Shichiri M, Marumo F: Secretory mechanism of immunoreactive endothelin in cultured bovine endothelial cells. Biochem Biophys Res Commun 1989, 160:93-100

21. Wong S, Brennan FE, Young MJ, Fuller PJ, Cole TJ: A direct effect of aldosterone on endothelin-1 gene expression in vivo. Endocrinology 2007, 148:1511-1517

22. Hinson JP, Kapas S, Teja R, Vinson GP: Effect of the endothelins on aldosterone secretion by rat zona glomerulosa cells in vitro. J Steroid Biochem Mol Biol 1991, 40:437-439

23. Deliyanti D, Armani R, Casely D, Figgett WA, Agrotis A, WilkinsonBerka JL: Retinal vasculopathy is reduced by dietary salt restriction: involvement of Glia, ENaCalpha, and the renin-angiotensinaldosterone system. Arterioscler Thromb Vasc Biol 2014, 34: 2033-2041

24. Deliyanti D, Miller AG, Tan G, Binger KJ, Samson AL, WilkinsonBerka JL: Neovascularization is attenuated with aldosterone synthase inhibition in rats with retinopathy. Hypertension 2012, 59:607-613

25. Wilkinson-Berka JL, Tan G, Jaworski K, Miller AG: Identification of a retinal aldosterone system and the protective effects of mineralocorticoid receptor antagonism on retinal vascular pathology. Circ Res 2009, 104:124-133

26. Moravski CJ, Kelly DJ, Cooper ME, Gilbert RE, Bertram JF, Shahinfar S, Skinner SL, Wilkinson-Berka JL: Retinal neovascularization is prevented by blockade of the renin-angiotensin system. Hypertension 2000, 36:1099-1104

27. Wingler K, Wunsch S, Kreutz R, Rothermund L, Paul M, Schmidt HH: Upregulation of the vascular NAD(P)H-oxidase isoforms Nox 1 and Nox 4 by the renin-angiotensin system in vitro and in vivo. Free Radic Biol Med 2001, 31:1456-1464

28. An SJ, Boyd R, Zhu M, Chapman A, Pimentel DR, Wang HD NADPH oxidase mediates angiotensin II-induced endothelin-1 expression in vascular adventitial fibroblasts. Cardiovasc Res 2007, 75:702-709

29. Chen DD, Dong YG, Yuan H, Chen AF: Endothelin 1 activation of endothelin A receptor/NADPH oxidase pathway and diminished antioxidants critically contribute to endothelial progenitor cell reduction and dysfunction in salt-sensitive hypertension. Hypertension 2012, 59:1037-1043 
30. Dammanahalli KJ, Sun Z: Endothelins and NADPH oxidases in the cardiovascular system. Clin Exp Pharmacol Physiol 2008, 35:2-6

31. Howell GR, Macalinao DG, Sousa GL, Walden M, Soto I, Kneeland SC, Barbay JM, King BL, Marchant JK, Hibbs M, Stevens B, Barres BA, Clark AF, Libby RT, John SW: Molecular clustering identifies complement and endothelin induction as early events in a mouse model of glaucoma. J Clin Invest 2011, 121:1429-1444

32. Deliyanti D, Zhang Y, Khong F, Berka DR, Stapleton DI, Kelly DJ, Wilkinson-Berka JL: FT011, a novel cardiorenal protective drug, reduces inflammation, gliosis and vascular injury in rats with diabetic retinopathy. PLoS One 2015, 10:e0134392

33. Deliyanti D, Wilkinson-Berka JL: Inhibition of NOX1/4 with GKT137831: a potential novel treatment to attenuate neuroglial cell inflammation in the retina. J Neuroinflammation 2015, 12:136

34. Wilkinson-Berka JL, Deliyanti D, Rana I, Miller AG, Agrotis A, Armani R, Szyndralewiez C, Wingler K, Touyz RM, Cooper ME, Jandeleit-Dahm KA, Schmidt HH: NADPH oxidase, NOX1, mediates vascular injury in ischemic retinopathy. Antioxid Redox Signal 2014, 20:2726-2740

35. Gien J, Tseng N, Seedorf G, Kuhn K, Abman SH: Endothelin-1-Rho kinase interactions impair lung structure and cause pulmonary hypertension after bleomycin exposure in neonatal rat pups. Am J Physiol Lung Cell Mol Physiol 2016, 311:L1090-L1100

36. An SJ, Boyd R, Wang Y, Qiu X, Wang HD: Endothelin-1 expression in vascular adventitial fibroblasts. Am J Physiol Heart Circ Physiol 2006, 290:H700-H708

37. Vecino E, Rodriguez FD, Ruzafa N, Pereiro X, Sharma SC: Glianeuron interactions in the mammalian retina. Prog Retin Eye Res 2016, 51:1-40

38. Karlstetter M, Ebert S, Langmann T: Microglia in the healthy and degenerating retina: insights from novel mouse models. Immunobiology 2010, 215:685-691

39. Goncalves A, Ambrosio AF, Fernandes R: Regulation of claudins in blood-tissue barriers under physiological and pathological states. Tissue Barriers 2013, 1:e24782

40. Reichenbach A, Bringmann A: New functions of Muller cells. Glia 2013, 61:651-678

41. Zong H, Ward M, Madden A, Yong PH, Limb GA, Curtis TM, Stitt AW: Hyperglycaemia-induced pro-inflammatory responses by retinal Muller glia are regulated by the receptor for advanced glycation end-products (RAGE). Diabetologia 2010, 53:2656-2666

42. Zhao X, Li Y, Lin S, Cai Y, Zhang J, Yu X, Yang H, Yang L, Chen X, Luo Y, Lu L: The effects of sonic hedgehog on retinal muller cells under high-glucose stress. Invest Ophthalmol Vis Sci 2015, 56: $2773-2782$

43. Moravski CJ, Skinner SL, Stubbs AJ, Sarlos S, Kelly DJ, Cooper ME, Gilbert RE, Wilkinson-Berka JL: The renin-angiotensin system influences ocular endothelial cell proliferation in diabetes: transgenic and interventional studies. Am J Pathol 2003, 162:151-160

44. Zhao M, Celerier I, Bousquet E, Jeanny JC, Jonet L, Savoldelli M, Offret O, Curan A, Farman N, Jaisser F, Behar-Cohen F: Mineralocorticoid receptor is involved in rat and human ocular chorioretinopathy. J Clin Invest 2012, 122:2672-2679

45. Aveleira CA, Lin CM, Abcouwer SF, Ambrosio AF, Antonetti DA: TNF-alpha signals through PKCzeta/NF-kappaB to alter the tight junction complex and increase retinal endothelial cell permeability. Diabetes 2010, 59:2872-2882

46. Ishibashi T, Hata Y, Yoshikawa H, Nakagawa K, Sueishi K, Inomata $\mathrm{H}$ : Expression of vascular endothelial growth factor in experimental choroidal neovascularization. Graefes Arch Clin Exp Ophthalmol 1997, 235:159-167

47. Maguire JJ, Davenport AP: ETA receptor-mediated constrictor responses to endothelin peptides in human blood vessels in vitro. Br J Pharmacol 1995, 115:191-197
48. Sarthy VP, Sawkar H, Dudley VJ: Endothelin2 induces expression of genes associated with reactive gliosis in retinal Muller cells. Curr Eye Res 2015, 40:1181-1184

49. Yang X, Dong X, Jia C, Wang Y: Profiling of genes associated with the murine model of oxygen-induced retinopathy. Mol Vis 2013, 19: $775-788$

50. Braunger BM, Ohlmann A, Koch M, Tanimoto N, Volz C, Yang Y, Bosl MR, Cvekl A, Jagle H, Seeliger MW, Tamm ER: Constitutive overexpression of Norrin activates Wnt/beta-catenin and endothelin-2 signaling to protect photoreceptors from light damage. Neurobiol Dis 2013, 50:1-12

51. Wilkinson-Berka JL, Agrotis A, Deliyanti D: The retinal reninangiotensin system: roles of angiotensin II and aldosterone. Peptides 2012, 36:142-150

52. Chaturvedi N, Porta M, Klein R, Orchard T, Fuller J, Parving HH, Bilous R, Sjolie AK; DIRECT Programme Study Group: Effect of candesartan on prevention (DIRECT-Prevent 1) and progression (DIRECT-Protect 1) of retinopathy in type 1 diabetes: randomised, placebo-controlled trials. Lancet 2008, 372:1394-1402

53. Sjolie AK, Klein R, Porta M, Orchard T, Fuller J, Parving HH, Bilous R, Aldington S, Chaturvedi N: Retinal microaneurysm count predicts progression and regression of diabetic retinopathy. Post-hoc results from the DIRECT Programme. Diabet Med 2011, 28:345-351

54. Kawaguchi H, Sawa H, Yasuda H: Endothelin stimulates angiotensin I to angiotensin II conversion in cultured pulmonary artery endothelial cells. J Mol Cell Cardiol 1990, 22:839-842

55. Zeng ZP, Naruse M, Guan BJ, Naruse K, Sun ML, Zang MF, Demura H, Shi YF: Endothelin stimulates aldosterone secretion in vitro from normal adrenocortical tissue, but not adenoma tissue, in primary aldosteronism. J Clin Endocrinol Metab 1992, 74:874-878

56. Mazzocchi G, Rebuffat P, Gottardo G, Meneghelli V, Nussdorfer GG: Evidence that both ETA and ETB receptor subtypes are involved in the in vivo aldosterone secretagogue effect of endothelin-1 in rats. Res Exp Med (Berl) 1996, 196:145-152

57. Kim JH, Kim JH, Yu YS, Kim DH, Kim KW: Recruitment of pericytes and astrocytes is closely related to the formation of tight junction in developing retinal vessels. J Neurosci Res 2009, 87: 653-659

58. Li J, Wang JJ, Yu Q, Chen K, Mahadev K, Zhang SX: Inhibition of reactive oxygen species by Lovastatin downregulates vascular endothelial growth factor expression and ameliorates blood-retinal barrier breakdown in $\mathrm{db} / \mathrm{db}$ mice: role of NADPH oxidase 4. Diabetes 2010, 59:1528-1538

59. Wang H, Yang Z, Jiang Y, Hartnett ME: Endothelial NADPH oxidase 4 mediates vascular endothelial growth factor receptor 2 -induced intravitreal neovascularization in a rat model of retinopathy of prematurity. Mol Vis 2014, 20:231-241

60. Goraca A, Kleniewska P, Skibska B: ET-1 mediates the release of reactive oxygen species and TNF-alpha in lung tissue by protein kinase C alpha and beta1. Pharmacol Rep 2016, 68:121-126

61. Deng W, Baki L, Baumgarten CM: Endothelin signalling regulates volume-sensitive $\mathrm{Cl}$ - current via NADPH oxidase and mitochondrial reactive oxygen species. Cardiovasc Res 2010, 88:93-100

62. Gray SP, Jha JC, Kennedy K, van Bommel E, Chew P, Szyndralewiez C, Touyz RM, Schmidt HH, Cooper ME, JandeleitDahm KA: Combined NOX1/4 inhibition with GKT137831 in mice provides dose-dependent reno- and atheroprotection even in established micro- and macrovascular disease. Diabetologia 2017, 60: 927-937

63. Aoyama T, Paik YH, Watanabe S, Laleu B, Gaggini F, FiorasoCartier L, Molango S, Heitz F, Merlot C, Szyndralewiez C, Page P, Brenner DA: Nicotinamide adenine dinucleotide phosphate oxidase in experimental liver fibrosis: GKT137831 as a novel potential therapeutic agent. Hepatology 2012, 56:2316-2327 